\title{
Schöne Aussichten: Europa hat die Wahl
}

\author{
PHILIPP GENSCHEL
}

Die Europawahlen stehen bevor und viele haben Angst. Die Europäische Union ist nach Jahren der Krise in schlechter Verfassung. Die rechte Welle rollt. Euroskeptische Parteien haben schon bei den Europawahlen 2014 gut abgeschnitten und könnten noch einmal zulegen. Herrje! Ächzen, seufzen aller Orten. Dabei muss es nicht so kommen. Wir haben die Wahl!

In einer Rede im April 2018 hat der französische Präsident Emmanuel Macron von einem „europäischen Bürgerkrieg“ zwischen liberaler Demokratie und einem neuen autoritären Populismus gesprochen: die Europabefürworter gegen die Europagegner; die Guten gegen die Schlechten; das Licht gegen die Finsternis.

Die Zuspitzung erleichtert die politische Mobilisierung - aber leider für beide Seiten. Den ganzen Orbans, Kaczyńskis, Gaulands und Le Pens kann gar nichts Besseres passieren als ein Lagerwahlkampf, der es ihnen erspart, ihre inneren Konflikte auszutragen. Denn abgesehen von einer tief sitzenden Abneigung gegen die EU haben die Rechtspopulisten aus Nettozahler- und Nettoempfängerländern (Österreich vs. Ungarn), Gläubiger- und Schuldnerstaaten (Deutschland vs. Italien) oder Ländern mit und ohne Bootsflüchtlinge (Italien vs. Polen) kaum gemeinsame Interessen. Die rechten Populisten steigen auf die Zuspitzung deshalb begeistert ein. Der europapolitische Leitantrag der AfD reduziert die Wahl auf „funktionierende demokratische Nationalstaaten“ versus undemokratische EU und winkt mit dem Dexit als „letzte[r] Option“.

Dexit? Echt jetzt? Wie sehr der Austritt die nationale Demokratie gefährdet, zeigt sich am Brexit. Nicht einmal die Befürworter erwarten noch irgendwelche politischen oder ökonomischen Vorteile. Kontrolle haben sie für ihr Land nicht zurückgewonnen, dafür aber viele politische Optionen verspielt. Die nationale Demokratie braucht die EU. Das kann man jetzt mit bloßem Auge sehen und den Rechten um die Ohren schlagen.

Aber auch wenn man für die EU ist, muss man sie deshalb noch lange nicht nehmen, wie sie ist. Bei der Europawahl können wir zeigen, welche EU wir haben wollen.

Viele sozialdemokratische Kandidaten wollen vor allem eine soziale EU mit armutsfestem Mindestlohn, gemeinsamer Arbeitslosenversicherung und aktivierender Sozialpolitik. Gute Absicht, aber vielleicht der falsche Ansatz. Wie die Eurokrise zeigt, kann ein schlechter makro-ökonomischer Rahmen mehr sozialen Schaden anrichten, als jede noch so gut gemeinte sozialpolitische Koordinierung zu kompensieren vermag. Deshalb sollte man hier ansetzen. Die Währungsunion ist zehn Jahre nach Ausbruch der Eurokrise zwar wesentlich interventionistischer als vorher, trotzdem aber nur bedingt krisensicherer. Was nach wie vor fehlt, ist ausreichende finanzpolitische Solidarität, um zu verhindern, dass einzelne Mitgliedstaaten am Kapitalmarkt gegeneinander ausgespielt werden können. Das erfordert eine gewisse Vergemeinschaftung der Schuldenhaftung. Viele lehnen dies ab, gerade in Deutschland. Aber wer den Euro er- halten möchte, wie angeblich $83 \%$ aller Deutschen (Eurobarometer 2018), muss auch das dafür Erforderliche tun.

Eine weitere Richtungsentscheidung betrifft die Migrationspolitik. Nach der Flüchtlingskrise 2015 hat die EU die Verantwortung weitgehend an die Türkei und Libyen ausgelagert, in der Hoffnung wohl, es möge niemand mehr kommen. Aber ist das wirklich die Lösung? Das polnische Wirtschaftsministerium rechnet mit 5 Mio. weniger Polen im arbeitsfähigen Alter im Jahr 2050. Wer soll die Lücke füllen? Wenn der amerikanische Abzug aus Syrien zu einer neuen Flüchtlingswelle führt, wie soll die EU reagieren?

Wie halten wir es mit Europas Sicherheit? Die geopolitische Lage wird schwieriger, die Belastbarkeit der NATO nimmt ab. Emmanuel Macron will eine „echte europäische Armee“. Ist das gut? Durch welche Mechanismen könnte solch eine Armee politisch kontrolliert werden? Und welche Mitgliedstaaten würden dabei mitmachen? Überhaupt, die Grenzen! Die EU hat sich um eine abschließende Definition ihres Territoriums stets gedrückt. Das wird aber immer problematischer. Man muss entscheiden, ob nach der Balkanerweiterung noch was kommen soll, ob man den Türkeibeitritt endgültig ad acta legen will und ob immer alle Mitgliedstaaten an allen EU Politiken teilnehmen müssen. Bulgarien will in die Währungsunion. Muss das wirklich sein?

Wahlen sind nicht allein ein machtpolitisches Problem, sondern auch ein kognitives: Bevor man zwischen Alternativen entscheiden kann, muss man erstmal Alternativen sehen. Dies kann aus zwei Blickwinkeln geschehen. Man kann vom Bestehenden aus nach Möglichkeiten suchen, es in die Zukunft zu verlängern. Das macht der Experte. Oder man kann von der Zukunft aus nach Möglichkeiten der gegenwärtigen Realisierung suchen. Das macht der Visionär. Die EU hat visionär begonnen und ist im Laufe der Zeit immer expertokratischer geworden. Je weiter dieser Prozess ging, desto kleiner wurden die Wahlmöglichkeiten - bis in der Eurokrise nur noch Alternativlosigkeit blieb. Der Rechtspopulismus ist eine visionäre Herausforderung dieser TINA-Expertokratie (There is no alternative). Das ist beängstigend, weil die Orbans und Salvinis so überzeugende Erzähler einer besseren Zukunft sind (die gerne in der nationalen Vergangenheit liegen darf). Es ist aber auch die Chance, den eigenen europäischen Traum wieder zu entdecken. Da war doch was, oder?

PHILIPP GENSCHEL ist Professor für European Public Policy am Europäischen Hochschulinstitut in Florenz. Forschungsschwerpunkte: Internationale Politische Ökonomie, Europäische Integration, Global Governance.

philipp.genschel@eui.eu 